\title{
“NO CANTO DO MUNDO DO CAPITAL": SOBRE EXPERIÊNCIA, EDUCAÇÃO E ARTE
}

\author{
"IN THE CORNER OF THE WORLD OF CAPITAL": ABOUT \\ EXPERIENCE, EDUCATION AND ART
}

DOI: http://dx.doi.org/10.5965/1984317816012020034

Lislaine Sirsi Cansi

Universidade Federal de Pelotas

lislaine_c@yahoo.com.br

\begin{abstract}
RESUMO
Este artigo apresenta uma discussão a partir de uma prática permeada pelo conceito de experiência e pela sensibilidade. Para isso, o conceito de experiência é revisitado em autores como Jorge Larrosa (2015), Walter Benjamin (1994) e John Dewey (2010; 2011) e a "educação (do) sensível" é fundamentada a partir da reflexão de João Francisco Duarte Júnior (2010), voltada aos campos da Educação e da Arte. A prática ocorreu em um shopping em busca de experiência, foi nomeada como "No canto do mundo do capital", narrada no segundo momento do texto. Como fechamento, um eixo de sistematização da experiência relacionado aos aspectos sociais se desdobra para o campo da Arte, especificamente relacionado a categorias de obras dos artistas Andy Warhol (1928 - 1987), Maryam Jafri (1972), Andreas Gursky (1955), Albrecht Dürer (1471 - 1528), David Hockney (1937), Jeff Wall (1946), Nam June Paik (1932 - 2006) e Bruce Nauman (1941), e possibilita pensar em Educação. Nessa discussão, será estabelecida à prática uma relação teóricoreflexiva que a aponte como "experiência".
\end{abstract}

Palavras-chave: Experiência. Prática. Arte. Educação do sensível.

\section{ABSTRACT}

This paper presents a discussion based on a practice permeated by the concept of experience and sensitivity. For this, the concept of experience is revisited by authors such as Jorge Larrosa (2015), Walter Benjamin (1994) and John Dewey (2010; 2011) and the "sensitive (education)" is based on the reflection of João Francisco Duarte Junior (2010), focused on the fields of Education and Art. The practice took place in a mall in search of experience, was named as "In the corner of the world of capital", narrated in the second moment of the text. In closing, a systematization axis of experience related to social aspects unfolds into the field of Art, specifically related to categories of works by artists Andy Warhol (1928 - 1987), Maryam Jafri (1972), Andreas Gursky (1955), Albrecht Durer (1471 - 1528), David Hockney (1937), Jeff Wall (1946), Nam June Paik (1932 - 2006) and Bruce Nauman (1941), and make it possible to think about Education. In this discussion, it will be established to practice a theoretical-reflexive relationship that points to it as "experience".

Keywords: Experience. Practice. Art. Education of the sensitive. 


\section{INTRODUÇÃO}

Experiência, do latim experientia, denota ensaio, prova, tentativa, ato de experimentar, conhecimento adquirido por prática, estudos, observação, experimentação1. Assim compreende-se a experiência que podemos supor ter ao longo do tempo, a experiência transmitida e/ou obtida por meio de conhecimento abrangente e sistemático. É também a experiência que se experimenta, na qual sujeito e objeto se relacionam. Não é especificamente essa a experiência abordada nesse texto, embora versada de forma breve. Trata-se aqui da experiência como categoria conceitual não transmitida por alguém ou através do tempo, pertencente ao campo da Filosofia e articulada aos campos da Educação e da Arte.

A discussão proposta a partir desse pressuposto será norteada por meio das seguintes questões: o que é uma "experiência"? É admissível ter uma "experiência"? Como podemos apontar para algo e afirmar de que se trata de uma "experiência"? É plausível ensinar alguém a ter "experiência" e a experienciar? É possível ensinar de forma inclusiva alguém a ter "experiência" e a experienciar? É viável inserir a "experiência" ao processo educacional? E, por fim, todas as experiências educam? Esses questionamentos servirão de escopo para refletir de forma "rizomática" sobre experiência, Educação e Arte. Ressalta-se que o conceito de rizoma "conecta um ponto qualquer com outro ponto qualquer e cada um de seus traços não remete necessariamente a traços de mesma natureza [...], implica na conexão de pontos de qualquer natureza formando cadeias de ramificações" (DELEUZE; GUATTARI, 1995, p. 31), incorrendo em flexibilidade, dinamismo e abertura a outras possibilidades.

Para dar subsídio aos questionamentos discorridos, na próxima seção desse texto será discutido o conceito de "experiência" por meio de vozes de autores como Jorge Larrosa, Walter Benjamin e John Dewey. Em seguida, será narrada uma

\footnotetext{
${ }^{1}$ Retirado do Dicionário Priberam, disponível em <www.priberam.pt>, acesso em 05 mar. 2018.
} 
prática ${ }^{2}$ realizada em busca de experiência intitulada "No canto do mundo do capital". Por fim, na última seção será proposto um desdobramento da prática a partir de um eixo de sistematização articulado a categorias advindas do pensamento da Arte.

\section{SOBRE EXPERIÊNCIA, EDUCAÇÃO E ARTE}

Convém dar início à busca de compreensão do conceito de experiência por meio do pensamento do filósofo Jorge Larrosa (2015), sendo aquilo que toca, que passa e o que acontece com o sujeito e não aquilo que se passa, ou que o toca ou que the acontece de forma generalizada. O autor relata que "a experiência é cada vez mais rara, por falta de tempo" (LARROSA, 2015, p. 22) já que vivemos apressadamente, na velocidade do movimento constante dos ponteiros do relógio, ou melhor, na sutil e ligeira marcação digitalizada do tempo (que faz o tempo correr ainda mais). Nesse caso, frequentemente dizemos ficar sem tempo, como se esse fosse o saldo do dia, o tempo é visto para nós, sujeitos "sem tempo", como valor, como mercadoria que nos deixa sempre em dívida. $\mathrm{E}$, em dívida, não temos tempo para parar, para olhar vagarosamente, para perceber as coisas e nos aperceber nelas. Não temos tempo para termos experiência, já que não nos encontramos disponíveis. Diz Larrosa:

A experiência, a possibilidade de que algo nos aconteça ou nos toque, requer um gesto de interrupção, um gesto que é quase impossível nos tempos que correm: requer parar para pensar, parar para olhar, parar para escutar, pensar mais devagar, e escutar mais devagar; parar para sentir, sentir mais devagar, demorar-se nos detalhes, suspender a opinião, suspender o automatismo da ação, cultivar a atenção e a delicadeza, abrir os olhos e os ouvidos, falar sobre o que nos acontece, aprender a lentidão, escutar aos outros, cultivar a arte do encontro, calar muito, ter experiência e dar-se tempo e espaço (LARROSA, 2015, p. 25).

\footnotetext{
2 Atividade pedagógica proposta pela professora Maristani Polidori Zamperetti e intitulada como "EXPERIÊNCIA [IM]POSSÍVEL - Aprendendo com a nossa própria experiência", na disciplina "Seminário Avançado: Experiência e Arte na Formação Docente”, do Programa de Pós-Graduação em Educação (PPGE/UFPel), a qual tem como ementa discutir e estudar a experiência e a arte no processo de formação de professores, estabelecendo relações com os espaços e as condições necessárias para a sua potencialização e entender a experiência estética como promotora da educação do sensível a partir da arte e das vivências do cotidiano.
} 
Estar aberto à experiência para que "algo nos aconteça ou nos toque" corresponde a estar disponível à desordem, à incerteza, à falta de racionalização ao sentir, à percepção, ao prazer corporal, às possibilidades intersticiais, à relatividade, a um novo olhar, à memória, à imaginação, à fantasia, ao lúdico, à valorização das pequenezas do mundo, aos sentidos (sem o compromisso com as palavras prévias), à "desterritorialização" - compreendida como um processo de desorganização em que o sujeito abandona o seu território para reorganizar-se em outro território, à criação de outra territorialidade (DELEUZE apud BOUTANG, 1988-1989)³.

O "sujeito da experiência" se define "não por sua atividade, mas por sua passividade, por sua receptividade, por sua disponibilidade, por sua abertura" (LARROSA, 2015, p. 25-26). No entanto, estar aberto e disponível não significa ser "sujeito da informação", estando atento as mais diversas informações sobre o mundo e opinar excessivamente sobre tais informações, se expressando contra ou a favor delas. Opinar, dessa forma, soa como um dispositivo automático para que possamos nos posicionar frente a determinadas situações, considerando juízo de valor. Nada assim toca o sujeito, não passa pelo seu corpo, apenas o coloca em uma posição para responder algo de um dado momento para um momento específico. Para ser "sujeito da experiência" é relevante que o sujeito tenha consciência de que o "excesso de trabalho" também anula a sua experiência. Ter "experiência" não é sinônimo do desejo constante em fazer algo, até porque atividades em excesso implicam em querer e em fazer contínuo, em estado de movimento permanente na qual há a constituição de um sujeito sem tempo e na destruição da experiência (LARROSA, 2015).

Pensar sobre a destruição da experiência não é algo novo. Walter Benjamin (1994), no início do século XX, especificamente na década de 30, já discorria sobre o empobrecimento da experiência identificando a raridade de experiências em nosso mundo. O referido autor desenvolve sua reflexão apontando para a expansão da técnica como dado relevante que dá origem à miséria de experiência do homem e destaca que a experiência adquirida ao longo do tempo não é socializada pelo

\footnotetext{
3 Reflexão presente na dissertação de mestrado em Artes Visuais da autora (CANSI, 2016, p. 91-92).
} 
sujeito que a detém, não é relatada para o outro, não é transmitida como saber, nem em provérbios, nem em narrativas (BENJAMIN, 1994).

Cidiane Lobato (2011), em seu artigo intitulado Benjamin e a questão da experiência, atesta que, para Benjamin, "a verdade está na linguagem e somente pode ser interpretada objetivamente a partir e por causa da linguagem" (LOBATO, 2011, p. 117). Desse modo, compreende-se a importância e o contexto da transmissão da experiência de um sujeito ao outro. A autora expõe também que a Filosofia proposta por Benjamin se dá "através da construção de ideias" e "procura elaborar, salvar ou resgatar experiências que, mesmo quando antigas, comunicam aquilo que permanece e que, por isso mesmo, são capazes do novo naquele que se apropria delas..." (LOBATO, 2011, p. 118). Aponta-se aqui para a ressignificação de experiências que são resgatadas e comunicadas.

É a partir desse contexto que é possível compreender o personagem do velho da parábola que inicia o texto Experiência e Pobreza, de Benjamin (1994). O velho, em seu leito de morte, relata aos filhos a respeito da riqueza que possui em seus vinhedos. Seus filhos, em busca da riqueza do pai, cavam a terra e nada encontram nela. Porém, no momento de produção dos vinhedos percebem do que se trata a riqueza relatada pelo pai. Eles não consideraram o "saber da experiência" (LARROSA, 2015) do pai ao relatar nas entrelinhas que a riqueza seria o trabalho. Com isso, Benjamin (1994) destaca a pobreza das ações da experiência.

Acerca do empobrecimento da experiência John Dewey (2010) afirma que é possível não ter uma experiência quando a experiência vivida é incipiente. A incipiência particulariza-se pela distração e pela dispersão em relação ao que observamos, pensamos e desejamos, sendo nomeada pelo referido autor como interrupções externas ou letargia interna.

Retornando ao "sujeito da experiência", Larrosa (2015) sugere a possibilidade de pensá-lo como território, lugar, espaço. Seria algo como:

um território de passagem, algo como uma superfície sensível que aquilo que acontece afeta de algum modo, produz alguns afetos, inscreve algumas marcas, deixa alguns vestígios, alguns efeitos [...] um ponto de chegada, um lugar a que chegam as coisas, como um lugar que recebe o que chega e que, ao receber, Ihe dá lugar (LARROSA, 2015, p. 25). 
O sujeito da experiência seria, por fim, "um espaço onde tem lugar os acontecimentos" (LARROSA, 2015, p. 25). Compreende-se, dessa forma, que para ser "sujeito da experiência" é particularmente necessário que o sujeito se exponha e que tal exposição seja um lugar de duas vias, onde é possível receber algo e doar algo a partir das "afecções" sentidas pelo corpo e acionadas pelas coisas do mundo. Entende-se que "afecção" é diferente de "afetação": a afetação sugere o envolvimento do outro em seu processo, porém, não necessariamente implica em mudança no sujeito afetado. Já, a "afecção" indica ação recíproca e resulta em um corpo modificado por essa ação (DELEUZE; GUATTARI, 1992).

Nesse sentido, faz-se relevante rememorar Larrosa (2015) ao denominar a experiência como aquilo que nos toca, nos forma e também nos transforma, e Dewey (2010) ao condicionar a ideia de continuidade à experiência: "A experiência ocorre continuamente, porque a interação do ser vivo com as condições ambientais está envolvida no processo de viver" (DEWEY, 2010, p. 109). Dessa forma, aquilo que será experienciado pelo sujeito se remeterá a algo já vivido, já percebido como experiência, ou proveniente de outras experiências. Seria algo cíclico e linear, com um "fluxo que vai de algo para algo" e um percurso caracterizado com início, meio e “consecução", algo que se completa (DEWEY, 2010, p. 111).

A experiência, assim percebida, é uma experiência que nos faz reviver, recordar, rememorar e ressignificar algo que tínhamos como referência. Seria a experiência que, ao recordá-la, a abordamos com espontaneidade ao nomeá-la como "essa ou aquela" experiência. Uma briga, a comida de alguém que apreciamos e até algo insignificante pode ser alvo do discurso sobre "essa ou aquela" experiência. Quando dizemos "essa ou aquela" experiência "podemos constatar que uma propriedade e não outra foi suficientemente dominante, e que caracteriza a experiência como um todo" (Dewey, 2010, p. 112). Algo, portanto, será determinante "naquela" briga, "naquela" comida, "naquela" coisa insignificante. Sobre "essa ou aquela" experiência, o artista e professor Luciano Vinhosa concorda com Dewey ao afirmar que "vivida em seu decurso, desde o inicio até a sua plena consumação, a experiência será individualizada na consciência daquele que a realiza e a integra às outras experiências" (VINHOSA, 2011, p. 65). Dewey (2010) nomeia tal experiência 
como um "memorial duradouro" e a concebe como "experiência singular ou experiência real".

Dewey (2010) também aponta para outro tipo de experiência, a "experiência de pensamento". Essa experiência, compreendida como experiência intelectual, mantém a ideia de continuidade da "experiência singular". Para que uma experiência seja "experiência de pensamento" é preciso "tirar uma conclusão ou chegar a ela", sendo a conclusão "a consumação de um movimento", o que corrobora com a ideia de continuidade (DEWEY, 2010, p. 113). A consumação não acarreta em cessar algo ou ao fechamento de algo; remete ao ato de chegar ao fim, referindo-se ao processo. Ao observar algo por acontecer ou acontecendo é possível chegar a uma conclusão intelectual a respeito dessa coisa vista. O autor reconhece que "uma experiência de pensar tem sua própria qualidade estética" (DEWEY, 2010, p. 113), na medida em que ter uma experiência estética demanda interesse pelo fim, na consumação de um movimento intelectual. Pressupõe, portanto, interesse pelas "coisas-objetos"4 encontrados no caminho, bem como pelas ações e sentimentos em relação a essas "coisas-objetos" sendo estes obstáculos ou estímulos, pelas condições que retardam ou aceleram o seu avanço, considerando a sua influência para chegar ao fim e, requer, também, a ideia de que a chegada final se relaciona com todo o processo, sendo, a "culminação de um movimento contínuo" (DEWEY, 2010, p. 116). É relevante destacar que se esse processo não ocorrer, a experiência será inestética.

Pensar acerca da "experiência", sobre o seu conceito, suas modalidades, sobre ser "sujeito de experiência", sobre ter ou não ter uma "experiência", converge à reflexão sobre o "saber da experiência". Larrosa assegura que o "saber da experiência" é:

[...] o que se adquire no modo como alguém vai respondendo ao que vai lhe acontecendo ao longo da vida e no modo como vamos dando sentido ao acontecer do que nos acontece. No saber da experiência não se trata da verdade do que são as coisas, mas do sentido ou do sem-sentido do que nos acontece (LARROSA, 2015, p. 32).

\footnotetext{
4 Palavra-proposição da professora Renata Azevedo Requião, em sua disciplina intitulada Percursos, narrativas, descrições: mapas poéticos (2015), pertencente ao curso de Mestrado em Artes Visuais (PPGAVI UFPel), ao se referir às coisas que nos envolvem e que fazem sentido para nós.
} 
O "saber da experiência" se constitui por meio do par conhecimento e vida. Reitera-se aqui o exemplo do personagem do velho da parábola de Benjamin (1994). Compreende-se com clareza nessa passagem que o "saber da experiência" se dá na experiência adquirida ao longo do tempo e que é transmitida por meio de provérbios e de narrativas, ações sinalizadas como raras por Benjamin.

Em se tratando de Educação e de Arte na contemporaneidade, o "saber da experiência" é construído não tanto na ideia de que o professor transmita o seu saber aos estudantes, na ideia de contato e comunicação, mas na própria concepção da palavra "experiência" que implica em dar sentido ao que nos acontece (LARROSA, 2015). Faz-se necessário frisar que a palavra transmissão é um verbete caro no campo da Educação, já muito criticado e percebido em tom depreciativo ao ser comparado com outras ações como "mediação" e "construção" do conhecimento. Não se trata disso nesse texto. Aqui, há embasamento em Dewey ao se referir à indulgência excessiva na educação. O autor diz:

O educador não compreende o que deveria ter obtido através de suas próprias experiências passadas e também não acredita no fato de que toda experiência humana é fundamentalmente social, ou seja, envolve contato e comunicação. Em termos morais, a pessoa madura, em certas ocasiões, não tem o direito de sonegar aos mais jovens a capacidade de compreensão compatível com o que sua própria experiência lhe proporcionou (DEWEY, 2011, p. 39).

Dessa forma, o estudante, aqui entendido como todo e qualquer sujeito, a partir do par "experiência/sentido" (LARROSA, 2015) e do princípio de "continuidade" (DEWEY, 2010), constrói ao longo do tempo o seu "saber da experiência". Dewey (2011) salienta que a questão da continuidade discrimina experiências educativas das deseducativas. Destaca que se a experiência no espaço educacional fizer sentido ao estudante, essa experiência afetará as experiências subsequentes, alargando a sua capacidade de desenvolvimento, sendo, portanto, educativa.

No que concerne aos campos da Educação e da Arte, é adequado inserir a abordagem de João Francisco Duarte Junior (2010) sobre a "educação (do) sensível" no mundo contemporâneo. O autor reflete sobre a educação na contemporaneidade a partir de uma crítica à educação na modernidade, em que 
fomos educados "para a obtenção do conhecimento inteligível (abstrato, genérico e cerebral) e deseducados no que tange ao saber sensível (concreto, particular e corporal)" (DUARTE JUNIOR, 2010, p. 26). Para Duarte Jr. (2010), atividades básicas da vida, automatizadas por nós, indicam a deseducação da sensibilidade. É necessário ter consciência que estamos "sem tempo", que estamos sendo engolidos por ele, que estamos "maquinizando" a vida e, portanto, não disponibilizando espaço para o saber sensível.

Duarte Jr. propõe a "educação (do) sensível" para além da "transmissão de conhecimentos formais e reflexivos acerca da Arte" (DUARTE JUNIOR, 2010, p. 29) via explicações, ensino da História da Arte e interpretação de obras de arte. O autor explica que a educação estésica pressupõe:

um esforço educacional que carregue em si mesmo, em métodos e parâmetros, aquela sensibilidade necessária para que a dimensão sensível dos educandos seja despertada e desenvolvida. A educação precisa ser suficientemente sensível para perceber os apelos que partem daqueles a ela submetidos, mais precisamente de seu corpo, com suas expressões de alegria e desejo, de dor e tristeza, de prazer e desconforto (DUARTE JR., 2010, p. 30-31).

Percebe-se que o autor propõe algo para além da contemplação da arte. Trata-se de uma educação em que a arte direcione o olhar para o contexto, para as "coisas-objetos" locais e do mundo, instigando relações de sentido com essa realidade externa através de estímulos corporais, os nossos cinco sentidos, o visual, o tátil, o olfativo, o auditivo e o gustativo. Tal proposta conversa com a compreensão de educação a qual envolve processos em constante transformação com caráter emancipatório que promovem a formação humana na sua integralidade, o direito de aprender e permite a inserção social do sujeito e o exercício à cidadania (BRASIL, 1988). Observa-se também que a proposição da "educação (do) sensível" para a Educação e o Ensino da Arte conversa com o "par experiência/sentido" de Larrosa (2015) e com o princípio de "continuidade" de Dewey (2010). Considerando que a Arte ocupa um lugar onde o oprimido pode encontrar espaços de resistência, é através da experiência e da educação estésica no espaço educacional que é possível, criar, inventar, dar sentido e descrever, narrar, contar com as próprias palavras e através de seu corpo. 
A seguir, será apresentada a prática realizada em busca de experiência, considerando a discussão anteriormente apresentada. Já que tal prática foi vivida por mim, opta-se em romper com a linguagem exposta até aqui para poder narrar à atividade a partir do sujeito que a experienciou. Dessa forma, o sujeito da narrativa passa a ser o sujeito no singular.

\section{PRÁTICA EM BUSCA DE EXPERIÊNCIA: "NO CANTO DO MUNDO DO CAPITAL"}

A narração da prática será apresentada em três momentos: o primeiro é composto pelas premissas, remetendo a aquilo que antecedeu a atividade, mas que já era compreendido como pertencente a ela. O segundo momento discorre sobre a atividade de fato contendo observações, sentimentos e pensamentos. Por fim, o terceiro momento sistematiza a prática e anuncia a relação que a define como experiência.

Em uma quarta-feira, dia 11 de outubro de 2017, chovia em Pelotas. Esta era a data prevista para vivenciar a prática. Para que tal prática pudesse ocorrer, considerei me despir das "coisas-objetos" do cotidiano e prestar atenção ao Outro, em um local público, sendo esse Outro, tudo aquilo que não fosse relacionado a mim. Havia uma semana que, via estímulo, estava compondo algo, alimentando e imaginando como poderia vir a ser essa prática. A abertura e a disponibilidade daria acesso ao "sujeito da experiência" (LARROSA, 2015).

Planejei estar em um local público da cidade que habitualmente não frequento para vivenciar a prática. Esse espaço, por não remeter a um espaço que chamo de meu, poderia potencializar o experimento proposto. Organizei objetos importantes e saí em direção ao shopping com objetivo definido: estar à espreita para observar um determinado local e as pessoas que frequentariam o shopping. Acredito que era por volta das $15 \mathrm{~h} 20$.

Adentrei ao espaço do shopping pela porta localizada a direita da fachada principal. Essa entrada é preferencial, já que ao passar por ela se avista uma imagem bastante desejada por pesquisadores: estantes lotadas de livros, revistas e 
afins. As $15 \mathrm{~h} 37$ avistei uma poltrona confortável no lugar que denominei "um dos cantos do mundo do capital". Era a única poltrona disponível. Havia outros locais para sentar, todos sem encosto, o que me deixaria desconfortável mediante o espaço de tempo predeterminado para vivenciar a prática.

A primeira sensação foi a de estar em uma grande sala, limpa, confortável e decorada, algo como desejamos ter em nossa casa. Entretanto, a sala de estar continha transeuntes, adultos, crianças, barulho e ações similares bastante familiares em nosso cotidiano, mas nada fraternais e que dizem respeito à comunicação e ao convívio social (ou a falta dele): o aparelho celular era o objeto onipresente, nele, com ele, a partir dele - algumas espiadas no entorno.

Planejei estar à espreita e assim registrei em uma caderneta pensamentos, sentimentos, sensações, observações a respeito daquele canto do mundo, da grande e arrumada sala de estar em que me encontrava. As $16 \mathrm{~h} 38$ guardei os meus objetos e levantei da poltrona em busca de outras observações. Em um local próximo praticamente vazio, ainda no canto do mundo do capital, no mesmo instante de tempo, uma moça e eu puxamos as poltronas localizadas ao redor de uma mesma mesa. Constrangidas, olhamos uma para a outra sem saber o que dizer ou o que fazer. Eu, aberta à "experiência", convidei a moça para me fazer companhia. Sentamos lado a lado, duas desconhecidas, para apreciarmos um café. Dividir uma refeição, ação corriqueira, nem sempre é agradável entre estranhos. Lembrei-me de um minicurso sobre a metodologia da história oral e comecei a fazer perguntas para que ela pudesse se sentir a vontade. Conversamos por uma hora. Ela se chama Desirèe, é professora de Educação Física e terapeuta ocupacional. As 17h40 a prática em busca de experiência chegou ao fim.

A sistematização da prática pode ser fundamentada a partir de vários eixos de sistematização relevantes ao objeto de estudo, a experiência, são eles: aspectos sociais - consumo, modos de vestir, comportamento, uso de aparelhos tecnológicos, relações interpessoais, aspectos sonoros - barulhos que se atravessam e que podem passar despercebidos na correria do cotidiano, aspectos estéticos - cores, texturas, agrupamento, contraste, configuração do ambiente e aspectos corporais percepção consciente de meu corpo no local (CIDAC; HOLLIDAY, 2007). Para esse 
texto, escolho fazer menção somente a algumas questões referentes aos aspectos sociais.

Primeiramente recupero o conceito sobre a "pobreza da experiência" de Benjamin (1994) para pensar acerca da fragilidade das relações interpessoais na contemporaneidade. O espaço que entendi como sala de estar estava excessivamente ocupado por diversas pessoas, grupos afins e grupos estranhos entre si. Havia pouca relação com o outro, para além do convívio social permitido e acessado pelo mundo virtual. Havia relação social mediada pelo uso do aparelho celular e certa maquinização de corpos. Questiona-se sobre a ocupação do espaço pelos transeuntes e a relação entre lugar e corpo permitida - e acessada, por eles. Questiona-se se esses sujeitos poderiam ser "sujeitos da experiência", se estavam experienciando algo ali ou se apenas estavam sendo sujeitos ativos do canto do mundo do capital.

Nesse contexto, evoco a recorrente frase de que a "experiência" para que seja "experiência" precisa nos tocar, nos atravessar, nos transformar e, para que sejamos "sujeitos de experiência" é necessário que sejamos sujeitos passivos, abertos, receptivos (LARROSA, 2015). Para esse momento, cito um nome próprio, “Desirèe", e me aproprio do pensamento do personagem Palomar (CALVINO, 1994), o qual compreende a ideia de que tudo no universo se liga e se corresponde, inclusive nós como sujeitos pensantes que agimos no mundo, tendo nossa imagem refletida (ou não), tendo consciência (ou não) de quem somos. A compreensão de que a experiência passa pelo corpo, que pode ser lembrada como "aquela" experiência, que se caracteriza pela ideia de continuidade e pela possibilidade de ser narrada indica que a prática pode ser entendida como experiência. A seguir será proposto como é possível inserir a arte advinda da prática em busca de experiência.

\section{O PENSAMENTO DA ARTE ADVINDO DA PRÁTICA}

A narração da prática em busca da experiência pressupõe consciência e olhar crítico frente às coisas observadas, sentidas e pensadas. A sistematização da experiência dá margem a desdobramentos em Educação e Arte e promove outras experiências. Dessa forma, considera-se a possibilidade de alargar a reflexão ao 
articular algum eixo de sistematização ao pensamento da arte. Trata-se do eixo relacionado aos aspectos sociais - consumo, modos de vestir, comportamento, uso de aparelhos tecnológicos, relações interpessoais - associados a artistas, por meio de categorias conceituais de suas obras.

Os artistas e as categorias são os seguintes: Andy Warhol (1928 - 1987), Maryam Jafri (1972) e Andreas Gursky (1955), sobre consumo; Albrecht Dürer (1471 - 1528), David Hockney (1937) e Jeff Wall (1946), no que diz respeito a comportamento e relações interpessoais; Nam June Paik (1932 - 2006) e Bruce Nauman (1941), concernente ao uso de aparelhos tecnológicos.

Em se tratando de consumo, seria inadequado não citar a obra de Andy Warhol. Na obra Campbell's Soup Cans, 1962 (Figura 1), o artista pintou produtos referentes à cultura de massa, por meio da apropriação e da repetição de produtos encontrados em prateleiras de supermercados, as sopas enlatadas. Warhol questionou o sistema capitalista que leva ao consumismo, inclusive o mercado da arte, modificou a função cotidiana da imagem do produto na medida em que um rótulo passou a ter o conceito de arte e fez provocações acerca dos estilos de vida (S/A, 2007; S/A, 2012b).

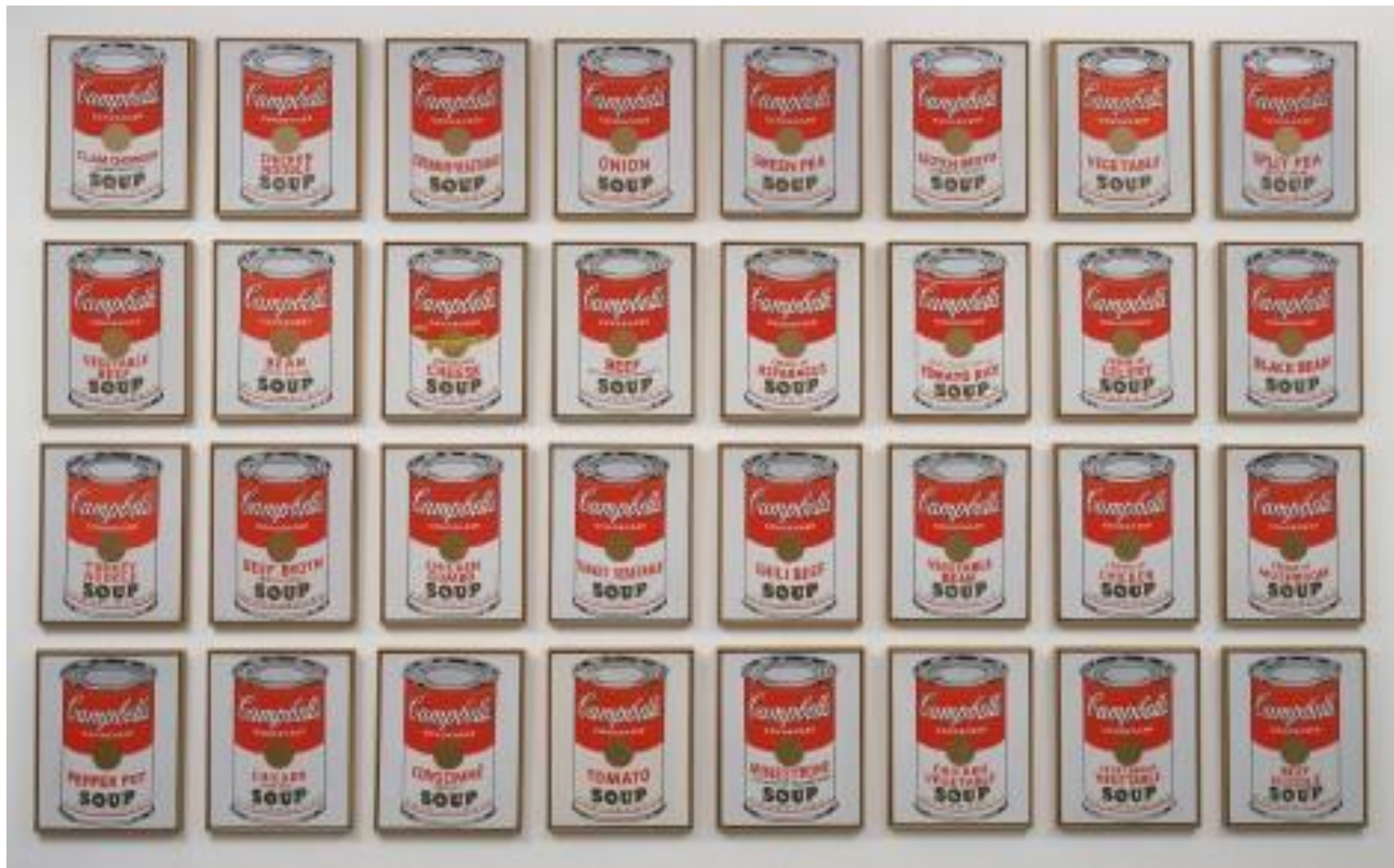

Figura 1: Campbell's Soup Cans, 1962, de Andy Warhol. 
Fonte: https://www.moma.org/learn/moma_learning/andy-warhol-campbells-soup-cans-1962

Maryam Jafri investiga fenômenos sociais como "arqueologias do conhecimento, a política de imagens e a produção de espaços" (VOLZ; REBOUÇAS,

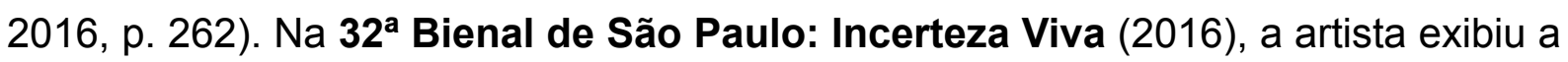
instalação Product Recaal: Na Index of Innovation [Recall de produtos: um índice da inovação], 2014-2015 (Figura 2), em que pesquisa lançamentos de produtos e projetos de pacotes fracassados ao longo da história, analisando como se dá a manipulação e a imposição do desejo do produto ao consumidor pela indústria alimentícia e pela publicidade. Em sua instalação, Jafri se apropria de alguns objetos e os apresenta com legendas, em uma montagem limpa, acentuando o contraste com o apelo visual publicitário, neutralizando emoções e desejos de tê-los e, dessa forma, possibilitando um distanciamento crítico (VOLZ; REBOUÇAS, 2016).

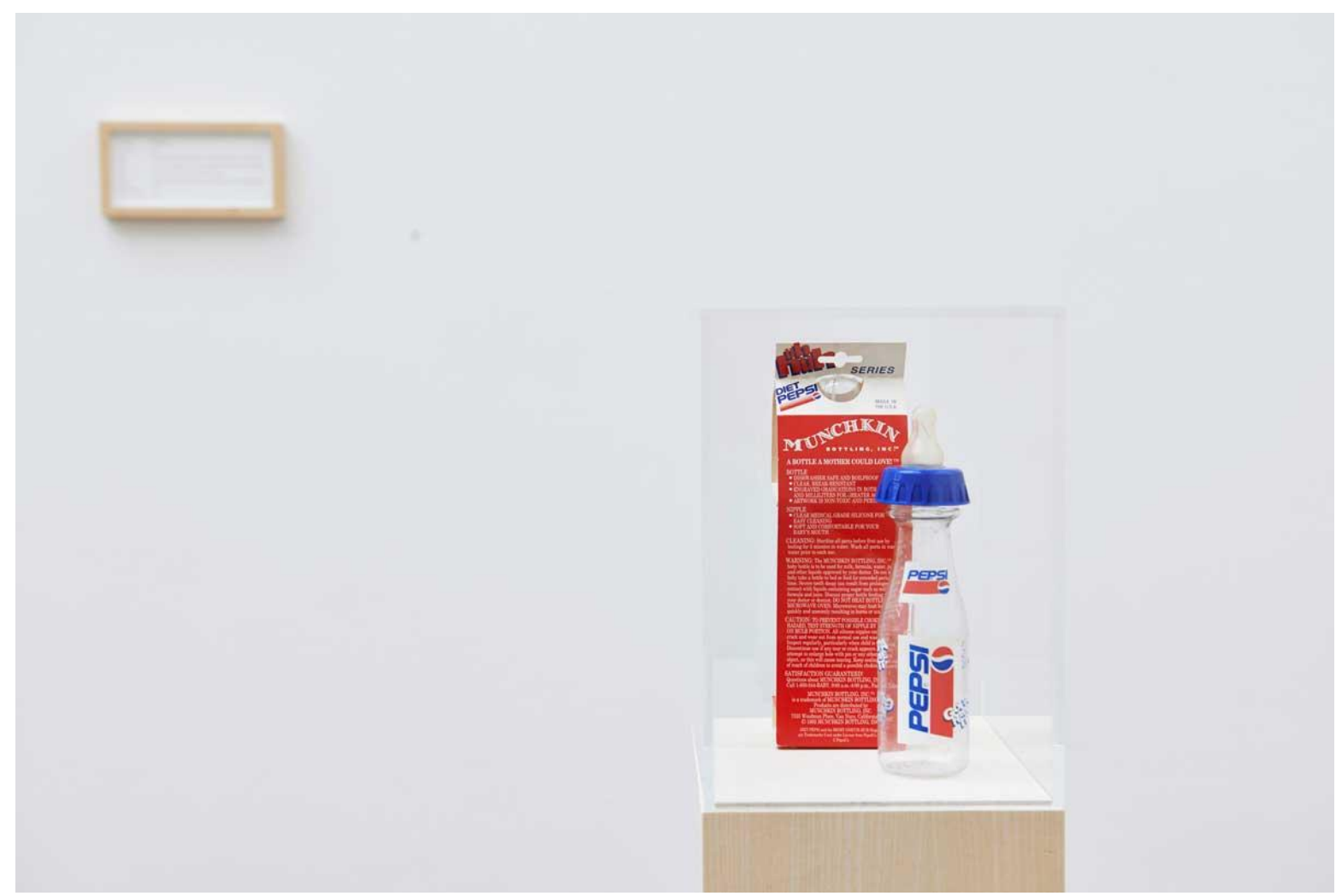

Figura 2: Product Recall: An Index of Innovation (fragmento), 2014-2015, de Maryam Jafri. Fonte: http://www.32bienal.org.br/pt/participants/o/2578 
Andreas Gursky investiga o mundo densamente povoado, mas o revela com a objetividade e o distanciamento de um alienígena. Na fotografia intitulada 99 centavos, 1999 (Figura 3), Gursky capta, através de uma câmera grande-angular, detalhes e a grandiosidade da imagem, tensionando questões contraditórias como escolher algum produto que aparenta ser ilimitado e, ao mesmo, é reduzido ao nível da mesmice, por se tratar de um múltiplo padronizado e que possui o mesmo valor comercial (S/A, 2012a).

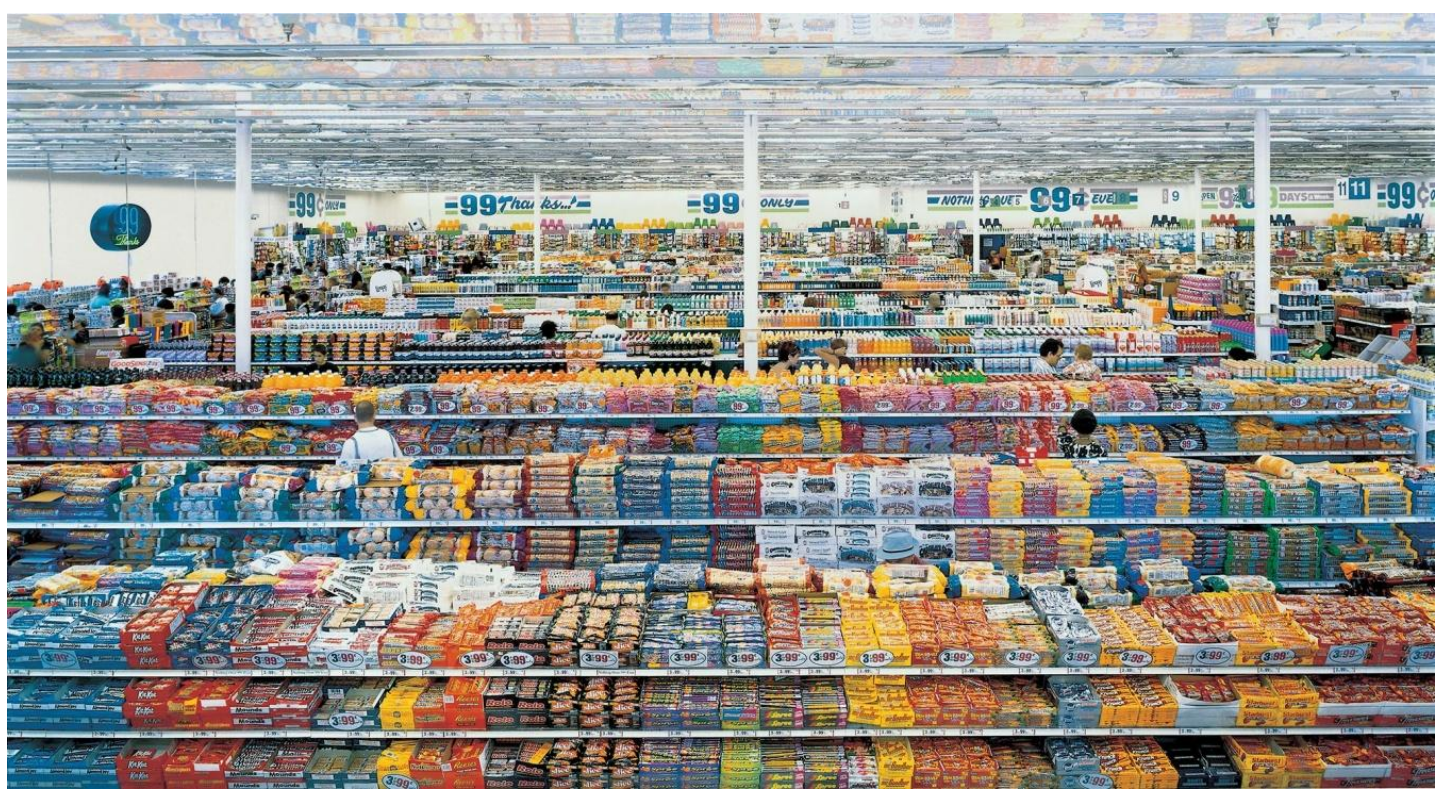

Figura 3: 99 centavos, 1999, de Andreas Gursky.

Fonte: https://www.google.com.br/search?q=Andreas+Gursky,+99+centavos

Em relação ao comportamento, Albrecht Dürer, reconhecido por realizar uma série de autorretratos no período renascentista, pintou seu Autorretrato com casaco de peles, 1500 (Figura 4), se representando com a aparência de Jesus Cristo por crer que, "um artista, quando se tornava um verdadeiro mestre, tinha tanta importância quanto Deus ou Jesus" (CANTON, 2004, p. 9). Os seus autorretratos indicam que o artista não se considerava um artesão, e sim um homem digno do mundo. 


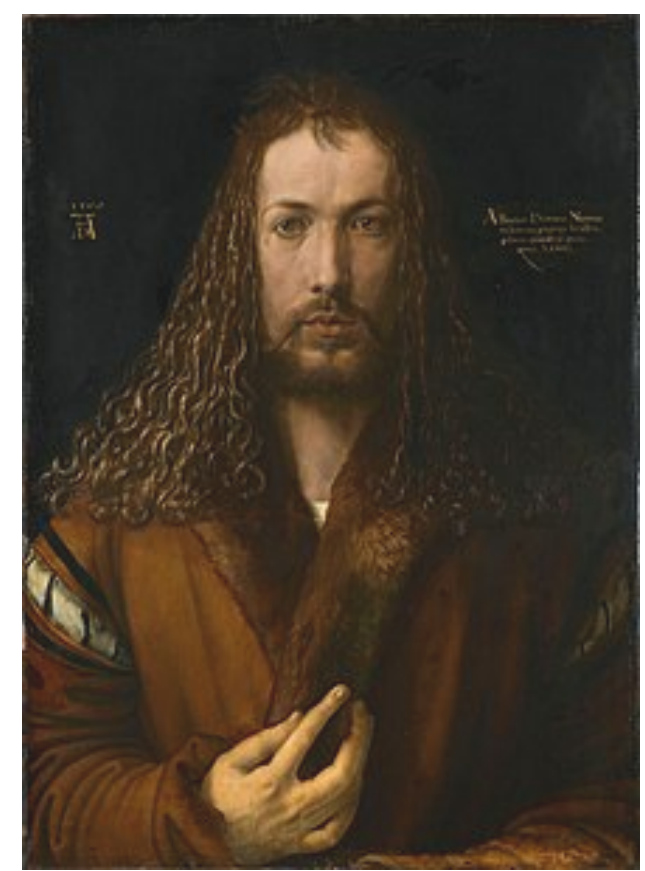

Figura 4: Autorretrato com casaco de peles, 1500, de Albrecht Dürer. Fonte: https://en.wikipedia.org/wiki/Albrecht_D\%C3\%BCrer

David Hockney, em O senhor e a senhora Clark e Percy, 1970-71 (Figura 5), retrata o designer de moda Ossie Clark e a sua esposa, a designer têxtil Celia Birtweel, recém-casados. Hockney destaca modos de vestir e uma época particular, através das roupas e das mobílias, e sugere relações interpessoais, a partir de um elemento simbólico, o gato, indicando infidelidade, e das posições dos retratados, a mulher em pé, dominante, o homem, sentado com o gato em seu colo. Ressalta-se que os designers produziram figurinos desejáveis nos anos 70 (GERLINGS, 2008). 


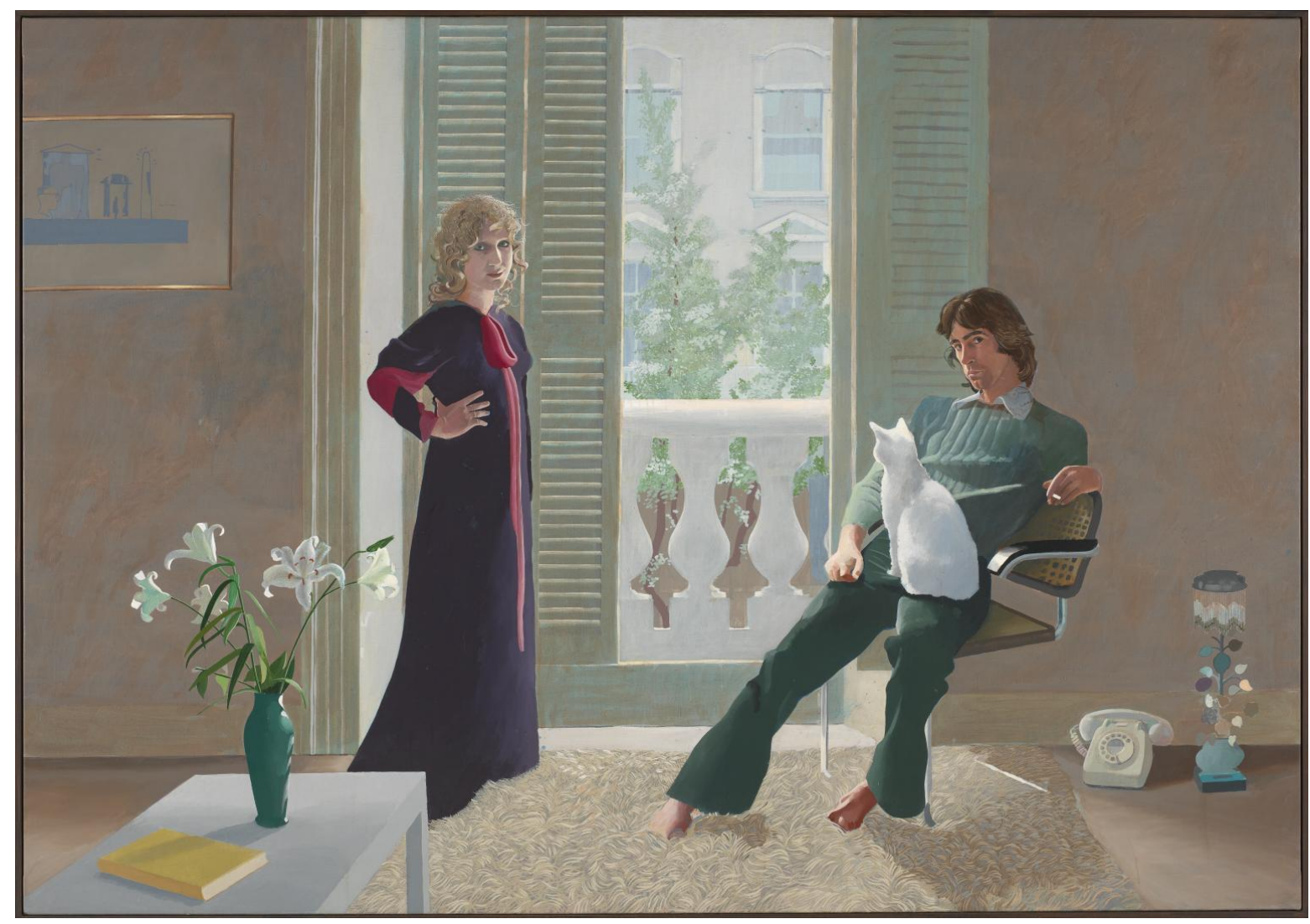

Figura 5: O senhor e a senhora Clark e Percy, 1970-71, de David Hockney. Fonte: https://www.tate.org.uk/art/artworks/hockney-mr-and-mrs-clark-and-percy-t01269

Jeff Wall, envolvido com a arte do passado, revela aspectos do mundo atual através da linguagem da fotografia, enquadrando-se na categoria denominada de "quadro-vivo" (COTTON, 2013). Nessa categoria os elementos necessários para o click fotográfico são arranjados a priori, desse modo compreende-se que as fotografias são "encenadas" ou "construídas". Aborda-se o uso da narrativa de uma história pela fotografia. Na obra Insônia, 1994 (Figura 6), Wall compõe a cena "por meio de recursos similares aos da pintura renascentista, em que os ângulos e os objetos de uma cena de cozinha nos orientam a percorrer o quadro e levam à compreensão da ação e da narrativa" (COTTON, 2013, p 50). Percebe-se que o homem que está deitado no chão está desperto, porém encontra-se alheio ao ambiente, dominado pela ansiedade (S/A, 2012a). Logo, a cena funciona como “alegoria de uma perturbação psicológica” (COTTON, 2013, p. 51). 


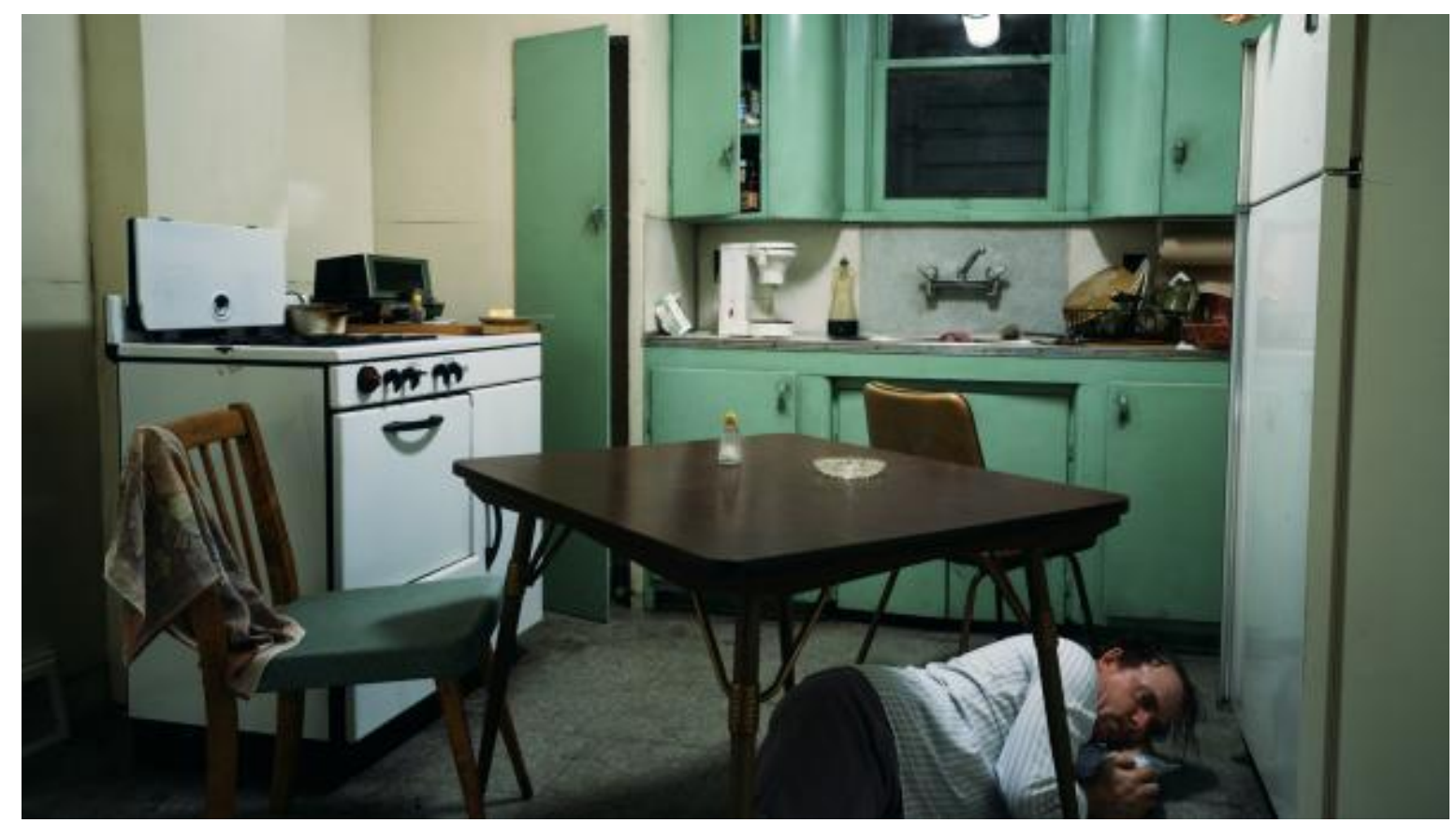

Figura 6: Insônia, 1994, fragmento, de Jeff Wall.

Fonte: http://br.rfi.fr/cultura/20110812-jeff-wall-em-bruxelas

Por fim, no que concerne ao uso de aparelhos tecnológicos, Nam June Paik é considerado um artista inovador. Em Nova York, 1965, Paik filmou o Papa e a sua comitiva e mostrou o resultado em um ponto de encontro de artistas, inaugurando a videoarte (RUSH, 2006). Em sua obra em colaboração com a música Charlotte Moorman, Concerto for TV, Cello and Video Tape. TC Cello Premier, 1971 (Figura 7), o artista "contesta constantemente a ideia de 'realidade' da imagem de televisão, ao colocar aparelhos de TV em posições inesperadas ou ao distorcer imagens na tela" (RUSH, 2006, p. 48). 


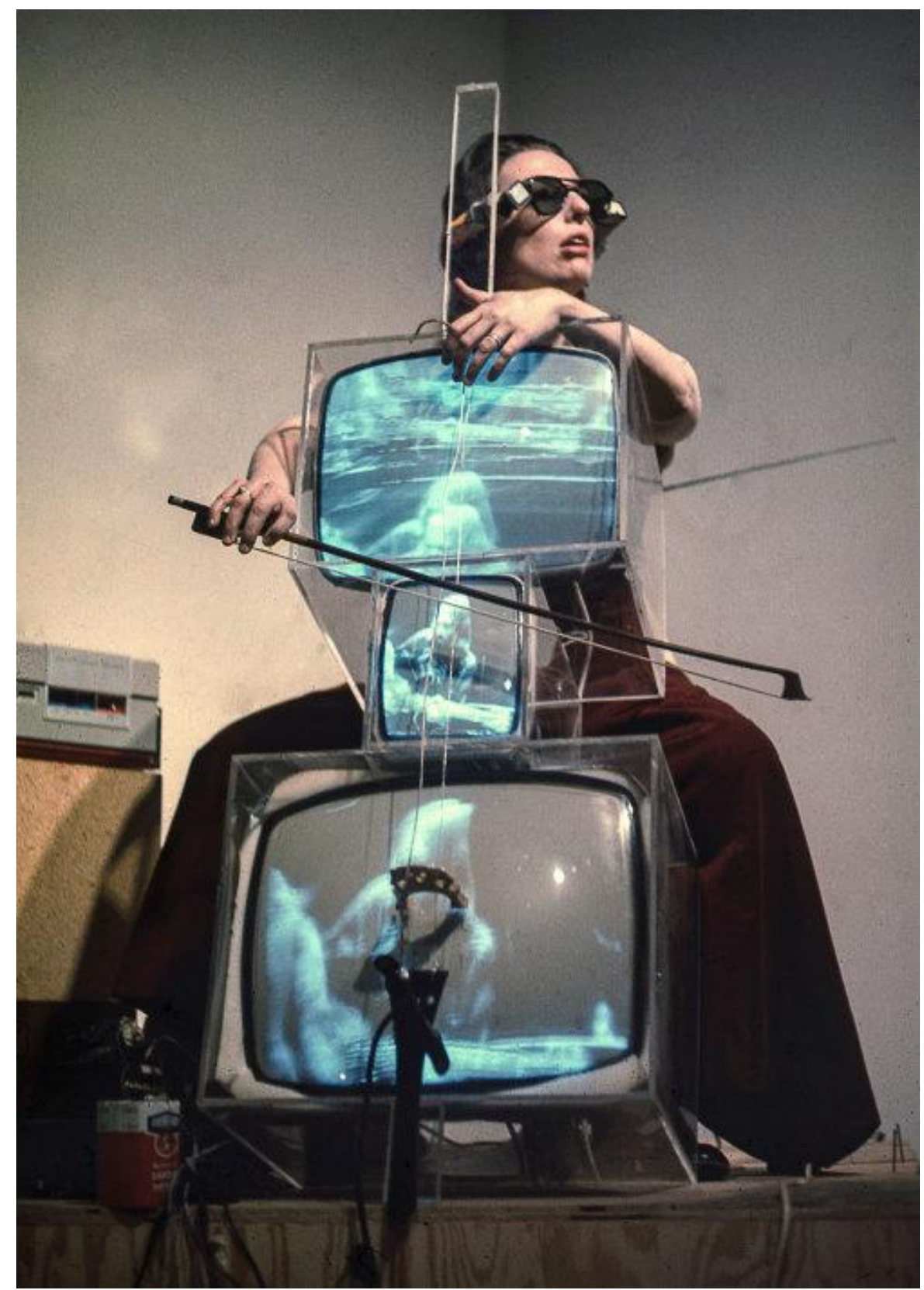

Figura 7: Concerto for TV, Cello and Video Tape. TC Cello Premier, 1971, de Nam June Paik. Fonte: https://www.tumblr.com/search/charlotte\%20\%20moorman

Bruce Nauman trabalha com uma variedade de linguagens artísticas, investiga as possibilidades da arte e direciona-se por meio de conceitos para produzir. Aqui, particularmente interessa a instalação de vídeo Anthro/Socio (Rinde Spinning), 1992 (Figura 8). Nessa obra o artista se ocupa de questionar a linguagem com a exibição de frases repetidas como "ajude-me, fira-me, sociologia; alimenteme, coma-me, antropologia" (RUSH, 2006, p. 43), por meio da voz de um sujeito em 
close que se vê em monitores e projeções na parede. A obra também examina o envolvimento do espectador na experiência da instalação.

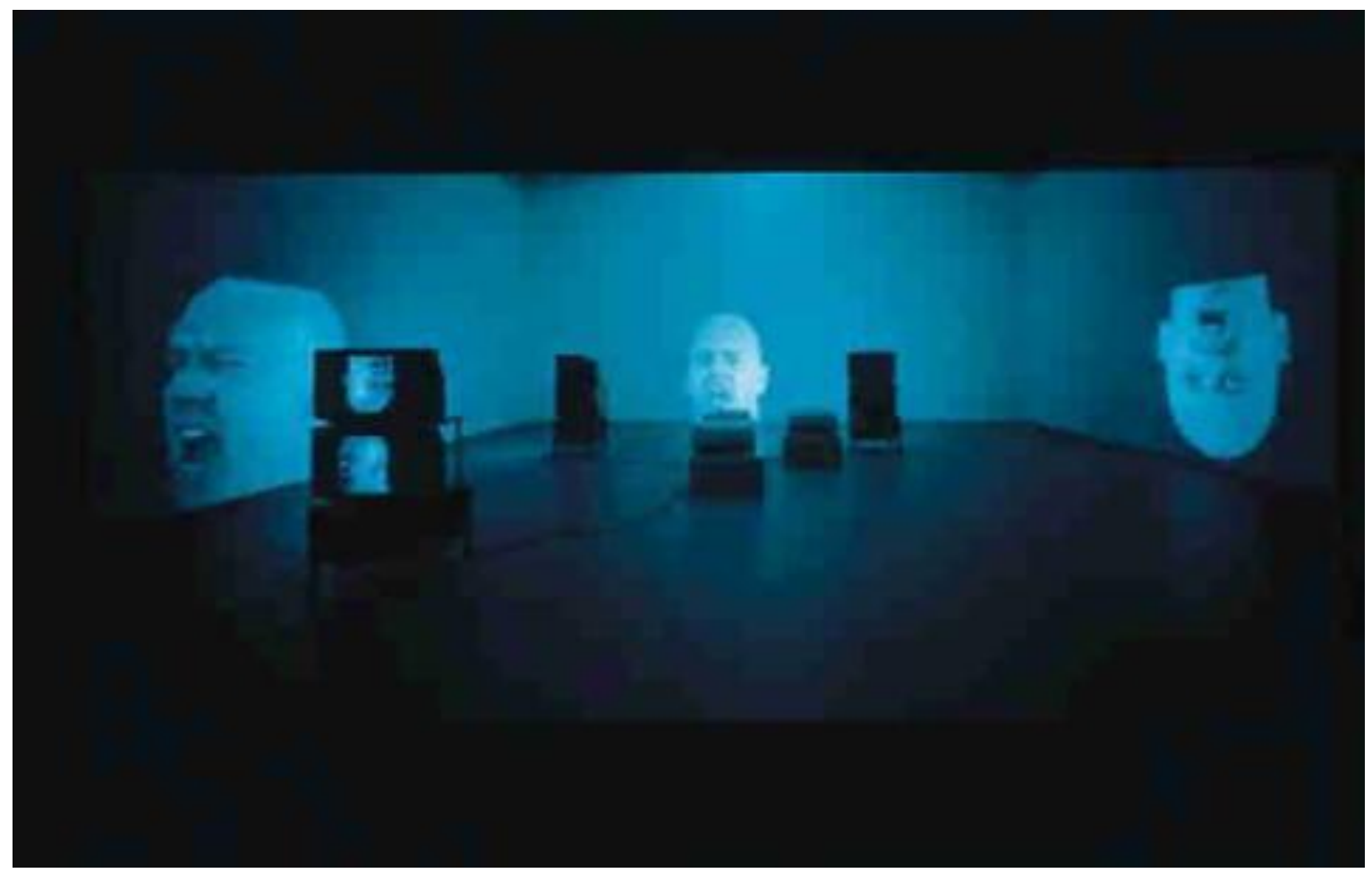

Figura 8: Anthro/Socio (Rinde Spinning), 1992, de Bruce Nauman.

Fonte: http://www.medienkunstnetz.de/works/anthro-socio/

A articulação entre aspectos sociais provenientes da prática em busca de experiência e o pensamento da arte se dá por meio de possibilidades reflexivas resultantes de categorias conceituais das obras. Tal articulação promove 0 pensamento para o espaço educacional, escolar e não escolar. Com Warhol, pensase acerca da ação artificial, repetida e automática de consumir o que o mercado impõe, ação observada no shopping, naquele pequeno canto do mundo do capital. Nesse contexto, Jafri nos ensina a ter atenção e olhar crítico em relação ao apelo visual publicitário. Em qualquer shopping, o apelo se encontra na organização das vitrines e no corpus das lojas. A partir da obra de Gursky, podemos questionar se estamos sendo engolidos por esse vasto e padronizado mercado chamado consumo e se temos escolha frente ao que é imposto.

O autorretrato de Dürer, primeiro autorretrato da história, tem o sentido de representar como se constitui o sujeito, no caso de Dürer, digno, ao se sentir artista 
e não artesão. No shopping havia selfies, os autorretratos da contemporaneidade. A partir da obra do referido artista podemos pensar o que a quantidade de selfies significa, em quem nós somos, o que queremos mostrar, o que desejamos deixar como legado e em como estamos nos constituindo e nos inserindo no mundo. Já, com a obra de Hockney, podemos refletir acerca de nossa postura no mundo, em modos de vestir, em modos de ser, em nossas relações interpessoais e nos ambientes os quais frequentamos. A propósito: que relações interpessoais perseverão? As relações provenientes do mundo virtual, de experiências, ambas, outras? Através da obra de Wall, podemos refletir a respeito de nossos "quadrosvivos", nas cenas que são construídas por nós, nas cenas que são arranjadas para nós. Podemos considerar pensar também nas cenas em que aparentemente estamos despertos, mas que interiormente estamos alheios, ansiosos, perturbados psicologicamente ao ambiente, às "coisas-objetos", às experiências, às relações.

As obras de Paik e de Nauman, por fim, nos ajudam a refletir sobre a realidade frente aos meios de comunicação de massa e nos direcionam a contestar acerca da repetição das ações cotidianas, sobre o que ouvimos, o que vemos, o que queremos ouvir e o que queremos ver.

\section{CONSIDERAÇÕES FINAIS}

Nesse artigo, foi proposto refletir acerca de questões que permeiam uma prática em busca de experiência, partindo do conceito de experiência e da educação do sensível, articulada, portanto à Educação e à Arte.

Revisitando os conceitos de experiência de autores como Larrosa (2015), em que a experiência pressupõe apreender e aprender, sendo agente de transformação de realidades, modificando a maneira de o sujeito ser, estar e pensar o mundo e o seu mundo, Dewey (2010), em que o princípio de continuidade se faz relevante para se ter uma experiência e Benjamin (1994), em que a linguagem qualifica uma experiência, foi possível pensar acerca da prática realizada.

Ser "sujeito da experiência" implica em estar à espreita, em estar aberto ao novo, em sentir a experiência corporalmente, em reviver a experiência como "aquela 
experiência". Recordo aqui que o objetivo inicial era estar à espreita, me observando e observando o espaço e as pessoas situadas nele, algo que esteve presente em todo o processo.

Avançando, refletir acerca de questões que permeiam a experiência denota transformá-la em linguagem, implica em narração, em fundamentação teórica, em sistematização, em articulações com áreas do conhecimento que nos são próximas, no caso, a Arte e a Educação. A prática ocorreu para que fosse possível fazer encaminhamentos sobre a educação do sensível. A partir da prática se observa o mundo, teoriza-se e se compreende o mundo em que vivemos. É preciso, para isso, consciência e olhar sensível e crítico.

Por fim, reconhecendo essas questões e tendo a compreensão de que a experiência passa pelo corpo, de que ela pode ser lembrada como "aquela" experiência, de que se caracteriza pela ideia de continuidade e pela possibilidade de ser narrada indica que a prática em busca de experiência pode ser apontada como uma "experiência", que aproxima educação e arte e enseja novas experiências em espaços educacionais, escolarizados ou não escolarizados.

\section{REFERÊNCIAS}

Arte: artistas, obras, detalhes, temas - 1960 em diante / [Dorling Kinderley]. São Paulo: Publifolha, 2012.

BENJAMIN, W. Experiência e Pobreza. In: BENJAMIN, W. Magia e Técnica, Arte e Política - ensaios sobre literatura e história da cultura. Obras escolhidas, volume I, 2 ed., São Paulo: Editora Brasiliense, 1994. Disponível em: <https://bibliotecasocialvirtual.files.wordpress.com/ 2010/06/walter-benjamin-experiencia-e-pobreza.pdf>. Acesso em: 30 set. 2017.

BOUTANG, P-A. O Abecederário de Gilles Deleuze. Entrevistas feitas com Gilles Deleuze por Claire Parnet e filmadas nos anos 1988-1989. Montpamasse, 1997. (vídeo). Online. Transcrição completa do vídeo disponível em: <http://stoa.usp.br/prodsubjeduc/files/ 262/1015/Abecedario+G.+Deleuze.pdf>. Acesso em: 05 jan. 2015.

BRASIL. Constituição da República Federativa do Brasil (1988). Brasília, DF: Senado Federal, 1988. Disponível em: <https://www2.senado.leg.br/bdsf/bitstream/handle/id/518231/ CF88_Livro_EC91_2016.pdf>. Acesso em: 30 nov. 2019.

CALVINO, I. Palomar. 2. ed. S/L: Companhia das Letras, 1994. Disponível em: <https:// estudanteuma.files.wordpress.com/2013/04/italo-calvino-palomar-rev-cc3b3pia-cc3b3pia.pdf >. Acesso em: 29 set. 2017.

CANTON, K. Espelho de artista: autorretrato. 3 ed. São Paulo: Cosac Naify, 2004. 
CANSI, Lislaine Sirsi. Poética na docência [corpo e território]. 2016. 215f. Dissertação (Mestrado em Artes Visuais) - Programa de Pós-Graduação em Artes Visuais, Centro de Artes, Universidade Federal de Pelotas, Pelotas, 2016.

CIDAC; HOLLIDAY, O. J. Sistematização de Experiências: aprender a dialogar com os processos. Rio de Janeiro: CIDAC; IPAD, 2007. Disponível em: <https://www.cidac.pt/files/ 4513/8497/5266/Aprendizagens_1_v_ligth.pdf>. Acesso em: 29 set. 2017.

Coleção Gênios da Arte: Warhol. Tradução de Mathias de Abreu Lima Filho. Baueri, SP: Girassol; Madri: Susaeta Ediciones, 2007.

COTTON, C. A fotografia como arte contemporânea. São Paulo: WMF Martins Fontes, 2013.

DELEUZE, G.; GUATTARI, F. Mil Platôs: capitalismo e esquizofrenia. Tradução de Ana Lúcia de Oliveira e Lúcia Cláudia Leão. São Paulo: Ed. 54, 1995.

O que é a Filosofia? Tradução de Bento Prado Junior e Alberto Alonso Muñoz. Rio de Janeiro: Ed. 34, 1992.

DEWEY, J. Arte como experiência. São Paulo: Martins Fontes, 2010.

Experiência e Educação. 2 ed. Petrópolis, RJ: Vozes, 2011.

DUARTE JR., J-F. A Montanha e o Videogame: escritos sobre educação. Campinas, SP: Papirus, 2010.

GERLINGS, C. 100 grandes artistas: uma viagem visual de Fra Angelico a Andy Warhol. Minas Gerais: Cedic, 2008.

Grandes Pinturas / [Dorling Kindersley]. Tradução de Maria da Anunciação Rodrigues. São Paulo: Publifolha, 2012.

LARROSA, J. Tremores: escritos sobre experiência. Belo Horizonte: Autêntica, 2015.

LOBATO, C. Benjamin e a questão da experiência. Cadernos Walter Benjamin, n. 7, Jul/ Dez. 2011. Disponível em: <http://www.gewebe.com.br/pdf/cad07/texto_cidiane.pdf>. Acesso em: 08 mar. 2018.

RUSH, M. Novas mídias na arte contemporânea. São Paulo: Martins Fontes, 2006.

VINHOSA, L. Obra de arte e experiência estética: arte contemporânea em questões. Rio de Janeiro: Apicuri, 2011.

VOLZ, J.; REBOUÇAS, J. (Orgs.). 32ª Bienal de São Paulo: Incerteza Viva: Guia. São Paulo: Fundação Bienal de São Paulo, 2016. 